Article

\title{
Resveratrol in Patients with Minimal Hepatic Encephalopathy
}

\author{
Giulia Malaguarnera ${ }^{1,2, *(1)}$, Manuela Pennisi ${ }^{3}$ (D) , Gaetano Bertino ${ }^{4}$, Massimo Motta ${ }^{3,4}$, \\ Antonio Maria Borzì ${ }^{1}$, Enzo Vicari ${ }^{4}$, Rita Bella ${ }^{5}$, Filippo Drago ${ }^{2}$ and \\ Michele Malaguarnera ${ }^{1,2}$ (iD \\ 1 Research Center "The Great Senescence", University of Catania, 95126 Catania, Italy; \\ antoniomaria.borzi@gmail.com (A.M.B.); michele.malaguarnera@gmail.com (M.M.) \\ 2 Department of Biomedical and Biotechnological Science, University of Catania, 95123 Catania, Italy; \\ f.drago@unict.it \\ 3 Spinal Unit of Cannizzaro Hospital, University of Catania, 95100 Catania, Italy; \\ manuelapennisi78@gmail.com (M.P.); mottam@unict.it (M.M.) \\ 4 Department of Experimental and Clinical Medicine, University of Catania, 95123 Catania, Italy; \\ gaetanobertinounict@gmail.com (G.B.); enzodante@email.it (E.V.) \\ 5 Department "G.F. Ingrassia", Section of Neurosciences, University of Catania, 95123 Catania, Italy; \\ rbella@unict.it \\ * Correspondence: giulia.malaguarnera@live.it; Tel.: +39-09-57262008; Fax: +39-09-57262011
}

Received: 15 December 2017; Accepted: 7 March 2018; Published: 9 March 2018

\begin{abstract}
Background: Minimal Hepatic Encephalopathy (MHE) is characterized by an impairment of social interaction, emotional behavior, sleep disorders, physical and mental symptoms, and diminished Quality of Life (QoL). The aim of our study is evaluating the potential liver health promoting a perspective of Resveratrol (RV) activities and evaluate whether RV treatment may improve health related quality of life (HRQL) and reduce depression and anxiety in patients with MHE. Methods: We evaluated depression using the Beck Depression Inventory test, anxiety with State-trait anxiety inventory test, quality of life through SF-36 test, and ammonia serum levels in 70 MHE patients that were randomized into two groups. Results: In the comparison between RV group and placebo group we observed a decrease in Back Depression Inventory (BDI) $(p<0.001)$, in State-trait anxiety inventory (STAI) $(p<0.001)$, and improve in physical function $(p<0.001)$, in role physical $(p<0.05)$, in body pain $(p<0.05)$, in general health $(p<0.001)$, in vitality $(p<0.05)$, and in social function $(p<0.001)$. Conclusions: Resveratrol showed efficacy in the treatment of depression, anxiety, and ammonia serum levels, and improved the quality of life Of MHE patients.
\end{abstract}

Keywords: depression; anxiety; resveratrol; ammonia; quality of life; minimal hepatic encephalopathy

\section{Introduction}

Minimal Hepatic Encephalopathy (MHE) is a frequent and common complication of cirrhosis, affecting nearly $80 \%$ of cirrhotic patients. Physical examination in MHE is often normal; patients may present subtle abnormalieties, interfering with executive function, including their working memory and orientation, impairment of social interaction, emotional behavior, sleep disorders, physical and mental symptoms, and diminished Quality of Life (QoL) [1].

This underrecognized and underdiagnosized syndrome often presents minimal changes in personality and in memory, intellectual function, concentration, and coordination.

These disorders impinge on the health related quality of life and have a negative prognostic value in relation to the occurrence of both bouts of overt hepatic encephalopathy and death [2]. 
Resveratrol (RV) is a natural phytoalexin, which is isolated from the roots of with hellebore (Veratrum grandiflorum Hoes). RV is present in two isoforms, cis/trans, and trans isomer is the biologically active one. It has been report that RV plays role as antinflammatory, antioxidants, antiviral, and exerts anticancer activities through many different mechanisms [3-11].

RV showed protective effect against neuro-inflammation inhibiting reactive oxygen species (ROS) production and mitogen-activated protein kinases (MAPK) signal transduction pathways, and also inactivating signalling pathways of both nuclear factor-kappa $b(\mathrm{NF}-\kappa \mathrm{B})$ and silent mating type information regulation 2 homolog 1 (SIRT1) [12,13]. SIRT belongs to a protein family consisting of seven individual members, which are involved in cellular metabolism, mitochondrial function, and stress responses modulation [14].

The RV attracted the interest of researchers for the combined antidepressant and anti-inflammatory effects [11].

The aim of the current study was the evaluation of RV in liver health, in health related quality of life (HRQL), and in reduction of depression and anxiety in patients with MHE.

\section{Patients and Methods}

\subsection{Study Design}

Seventy-five patients with cirrhosis and minimal cognitive impairment regarding selective attention and executive function were recruited between May 2013 and November 2016 at Cannizzaro Hospital in Catania (Italy).

The diagnosis of cirrhosis was based on case history, clinical examination, biochemical, endoscopic, and ultrasounds finding; or, when needed, on liver biopsy.

This observational study was approved by the research ethics committee of Cannizzaro Hospital.

All of the eligible patients were approached and asked to participate in the study; those who accepted signed the written the informed consent after reading carefully the patients information leaflet.

75 patients with diagnosis of MHE were enrolled in the study: three withdrew consent, two overt hepatic encephalopathy (Figure 1). The 70 patients were randomized into two groups, using permuted-block randomization with an allocation ratio 1:1 and block size of four. Random numbers were assigned according to the sequency of their inclusion and patients received respective study products. Group A were treated with RV in pills $19.8 \mathrm{mg}, \mathrm{N}$-acetyl cysteine $600 \mathrm{mg}$, lactoferrin $23.6 \mathrm{~g}$ (Resvis Alfa-sigma, Bologna, Italy). Group B were treated with placebo: N-acetyl cysteine $600 \mathrm{mg}$, lactoferrin $23.6 \mathrm{~g}$. The diagnosis of $\mathrm{HE}$ was made on the evaluation of consciousness, intellectual behavior, and neuromuscular functions. Mental status was assessed and graded on the basis of West-Haven Criteria [15]. The schedule was to receive for 90 days a supply of either RV or placebo. The measurement was made every month, both for efficacy and for tolerability tests.

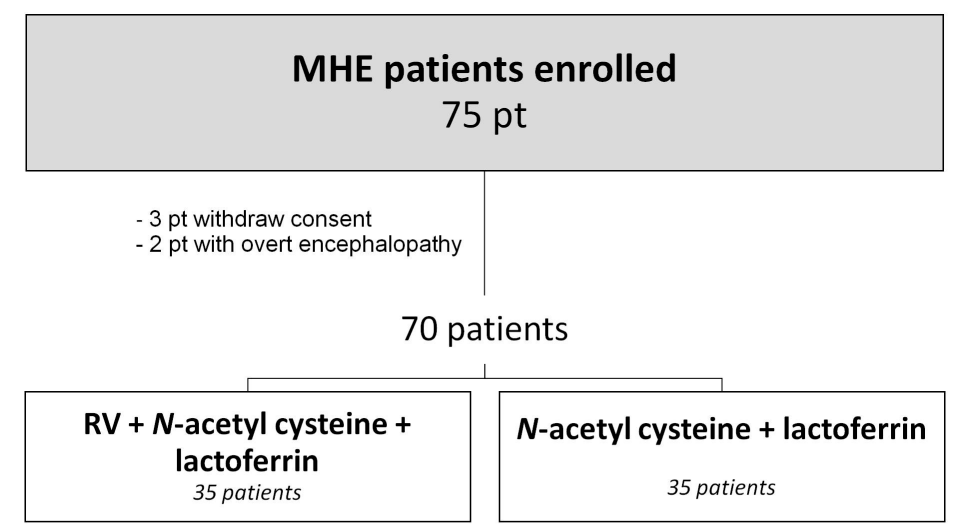

Figure 1. Study design. MHE = Minimal Hepatic Encephalopathy; RV=Resveratrol. 


\subsection{Protocol}

The inclusion criteria were age 25-65 years.

Cirrhotic patients who performed abnormally on psychometric tests but performed normally on clinical neuropsychiatric examination were diagnosed with MHE. MHE was diagnosed according to guidelines from the final report of the Working Party at the 11th World Congress of Gastroenterology in Vienna in 1998.

The exclusion criteria were: pregnancy and breast feeding; past history of overt hepatic encephalopathy $(\mathrm{OHE})$; use of interferon or psychoactive drugs, such as benzodiazepines, psychotropic drugs, antiepileptic; alcohol abuse, history of diabetes or renal impairment; significant head injury; arterial hypertension. Patients' characteristic included educational status, Child-Turcotte Pugh class, and etiology of cirrhosis [16].

Male patients were considered to have alcohol related cirrhosis if their alcohol intake was more than $50 \mathrm{~g}$ and female patients if their intake was more than $30 \mathrm{~g}$ for more than five years and if testing showed no viral metabolic or immunologic cause. Chronic hepatitis B and C were diagnosed when testing was positive for the viral markers Hepatitis B surface Antigen (HBsAg) and Hepatitis C virus antibody (anti-HCV) respectively.

All of the patients underwent to Psychometric Hepatic Encephalopathy Score (PHES) $[17,18]$, Short Form 36 Health Survey (SF-36) [19-22], Beck Depression Inventory (BDI) [23], and State-Trait Anxiety Inventory (STAI) [22].

\subsubsection{Diagnosis of $\mathrm{MHE}$}

The use of neuropsychometric battery tests have been limited to research of minimal HE. We performed the Psycometric Hepatic Encephalopathy Score (PHES), which consists of five psychometric tests that measure psychomotor speed and precision, visual perception, visus-spatial orientation, visual construction, concentration, attention, and memory $[17,18]$.

\subsubsection{Neuropsychological Testing}

\section{PHES Test Battery}

PHES Scores a neuropsychological battery composed of five different tests: Number connection test A (NET-A) and B (NET-B), line tracing test, serial dotting test, and digit symbol test $[15,16]$. The test detects attention and psychomotor speed, areas that were most affected by HE. PHES score is obtained based on sum of the result of each test $[17,18]$.

\subsubsection{SF-36 (Short Form-36 Health Survey)}

SF-36 questionnaire measures with eight domain scales and 36 items, health status. [17]

SF-36 provides two summary scores: physical component and mental component and eight health status scales: Physical functioning, role limitation due to physical problems, bodily pain, General health perceptions, vitality, social functioning, role limitation due to emotional problems, and mental health.

Patients completed the questionnaire and the resulting scores were transformed onto a scale from 0 (the worst possible score) to 100 (the best possible score), as recommended by questionnaires originators [19-22].

\subsubsection{Beck Depression Inventory (BDI)}

BDI is the most widely used instrument for detecting depression. It is a 21-item self report rating inventory that measures characteristic attitudes and symptoms of depression, including mood, sense of failure, pessimism, guilt, punishment, self-dissatisfaction, self dislike, self accusation, crying, suicidal ideas, irritability, social withdrawal, indecisiveness, body image change, and work difficulty. Each answer is scored from 0 to 3 . Higher total score indicate more severe depressive symptoms. Index 
score of $\leq 9$ is considered to be within normal range, a score of 10-15 shows minimal depressive symptomatology, a score of 16-31 points toward mild depression, a score of 32-47 is in favor of moderate depression, and a score of $>47$ indicates severe depression [23]. The maximum total score is 63, whereas the minimum is 0 .

\subsubsection{State-Trait Anxiety Inventory (STAI)}

Patients' anxiety was measured using the 20-items state-trait anxiety inventory (STAI). Each of 20 items related to anxiety was scored as 1 (not at all), 2 (somewhat), 3 (moderately), 4 (very much) with higher score indicating more anxiety.

The scale is scored by summing the 20 responses (range 20-80) [24].

\subsubsection{Clinical and Laboratory Assessment}

Medical history and physical examination had been performed for all patients. Laboratory tests included renal and liver function test, albumin, $\alpha$ fetoprotein, hemogram, prothrombin time index, fasting blood sugar, and venous ammonia concentration. The ammonia was determined according to the enxymatic determination of ammonia with glutamate dehydrogenase in a rapid and interference-free photometric determination (340 nanometer) of $\mathrm{NH}_{4}{ }^{+}$in native blood plasma as according to De Fonseca-Wollheim method [25]. Blood was immediately taken by refrigerated transport sent to the laboratory for determination within $15 \mathrm{~min}$ from blood sampling. To stage cirrhosis Child-Pugh score was carried out.

Cirrhosis and Viral etiology were evaluated, considering alcohol consumption for cirrhosis and measuring through ELISA HBsAg levels and anti HCV levels for viral tests. When indicated, medical examination for autoimmune liver disease, Wilson disease, hemochromatosis, and Budd-Chiari Syndrome were performed.

\subsubsection{Neurological Assessment}

Detailed neurological, psychiatric and mental state assessment had been performed to avoid undiagnosed psychiatric disorders.

\subsubsection{Efficacy and Tolerability Assessment}

The primary efficacy measures were changed at the beginning and at the end of the study period in aspartate aminotransferase (AST), alanine aminotransferase (ALT), gamma-glutamyl-transpeptidase $(\gamma$-GT), albumin, alkaline phosphatase (ALP), prothrombin time, and ammonia.

Laboratory assessments included hemochrome, glycemia, creatininemia, and blood urea were monitored at baseline and monthly until the end of the trial. Each subject of both the groups underwent ultrasonography (US) examination of the liver, electrocardiography, and blood pressure with the use of standard techniques [26].

\subsection{Statistical Analysis}

Descriptive statistics, chi-square tests (for categorical variables), and $t$-tests (for continuous variables) were used to compare demographic and clinical characteristics. $p$ values $\leq 0.05$ were considered to be statistically significant. Means, actual numbers, and percentages were used to describe data. Statistical Analyses were performed by two-way analysis of variance (ANOVA), as well as by controlling for Bonferroni's multiple correction.

\section{Results}

Demographics characteristics were similar between the two groups at baseline. At enrolment, no significant differences were observed in biohumoral tests, at etiologic factors in cirrhosis (Table 1). 


\subsection{Effects of RV on Biohumoral Findings}

In the group that were treated with RV, we observed a significant decrease $(p<0.001)$ in urea, in $\mathrm{NH} 4$, in AST, in ALT, and $\gamma$-GT.

In the placebo group we observed a decrease $(p<0.05)$ in AST and ALT.

The comparison between RV group and placebo group shows a significant decrease in NH4 $(p<0.001)$ in AST $(p<0.001)$ and in ALT $(p<0.001)$ (Table 2$)$.

Table 1. Clinical characteristics.

\begin{tabular}{lccc}
\hline \multicolumn{1}{c}{ Characteristics } & Resveratrol Group $\mathbf{3 5} \mathbf{~ p t}$ & Placebo Group 35 $\mathbf{p t}$ & $p$ \\
\hline Male/Female & $25 / 10$ & $23 / 12$ & N.S \\
Age (range) & $39-60$ & $35-60$ & N.S \\
SBP (mmHg) & $144.00 \pm 18.20$ & $145.00 \pm 19.10$ & N.S \\
DBP (mmHg) & $82.10 \pm 10.40$ & $81.80 \pm 10.50$ & N.S \\
Heart Rate (bpm) & $77 \pm 8$ & $75 \pm 9$ & N.S \\
BMI (kg/m ( $^{2}$ & $25.80 \pm 2.40$ & $26.10 \pm 2.70$ & N.S \\
Smokers/No Smokers & $15 / 20$ & $14 / 21$ & N.S \\
Cirrhosis etiology & & & \\
$\quad$ Post Hepatitis B & 10 & 11 & N.S \\
Post Hepatitis C & 16 & 14 & N.S \\
Alcoholism & 3 & 2 & N.S \\
$\quad$ Unknown & 6 & 8 & N.S \\
Child-Pugh Class & & & \\
$\quad$ Grade A & 20 & 19 & N.S \\
Grade B & 15 & 16 & N.S \\
\hline
\end{tabular}

SBP = Systolic Blood Pressure; DBP = Diastolic Blood Pressure; BMI: body mass index; N.S = not significant.

Table 2. Comparison of clinical parameters.

\begin{tabular}{|c|c|c|c|c|c|c|c|}
\hline \multirow{2}{*}{ Characteristics } & \multicolumn{2}{|c|}{ Resveratrol Group 35} & \multicolumn{4}{|c|}{ Placebo Group 35} & \multirow{2}{*}{$\begin{array}{c}\text { After RV } \rightarrow \text { Placebo } \\
p\end{array}$} \\
\hline & Before & After & $p$ & Before & After & $p$ & \\
\hline Urea & $51.80 \pm 6.10$ & $48.20 \pm 6.40$ & 0.019 & $51.40 \pm 5.90$ & $50.20 \pm 6.10$ & N.S & N.S \\
\hline Ammonia & $66.20 \pm 7.80$ & $41.40 \pm 6.80$ & $<0.001$ & $62.80 \pm 7.40$ & $59.70 \pm 6.70$ & N.S & $<0.001$ \\
\hline AST & $87.80 \pm 10.70$ & $40.40 \pm 9.80$ & $<0.001$ & $80.40 \pm 9.80$ & $75.20 \pm 8.70$ & 0.022 & $<0.001$ \\
\hline ALT & $96.40 \pm 11.80$ & $78.40 \pm 8.70$ & $<0.001$ & $91.70 \pm 10.20$ & $84.20 \pm 10.20$ & 0.003 & 0.013 \\
\hline$\gamma-\mathrm{GT}$ & $46.10 \pm 6.70$ & $40.40 \pm 6.40$ & $<0.001$ & $40.80 \pm 6.40$ & $40.50 \pm 6.10$ & N.S & N.S \\
\hline $\begin{array}{l}\text { Prothrombine } \\
\text { time }\end{array}$ & $15.40 \pm 1.80$ & $15.00 \pm 1.20$ & N.S & $15.50 \pm 1.70$ & $15.10 \pm 1.60$ & N.S & N.S \\
\hline Bilirubin & $2.00 \pm 0.40$ & $2.10 \pm 0.50$ & N.S & $2.10 \pm 0.40$ & $2.00 \pm 0.50$ & N.S & N.S \\
\hline Albumin & $3.50 \pm 0.50$ & $3.70 \pm 0.80$ & N.S & $3.60 \pm 0.50$ & $3.60 \pm 0.70$ & N.S & N.S \\
\hline
\end{tabular}

AST $=$ Aspartate aminotranferase; ALT $=$ alanine aminotransferase; $\gamma$-GT $=$ gamma-glutamyl transpeptidase; $\mathrm{RV}=$ Resveratrol; N.S = not significant.

\subsection{Effects of $R V$ in Depression, in Anxiety and in Quality of Life}

Anxiety and quality of life. The comparison between before and after RV treatment showed a decreased in BDI $p<0.001$ in STAI $(p<0.001)$ and increased in physical function $(p<0.001)$, in role physical $(p<0.05)$, in Body pain $(p<0.001)$, in general health $(p<0.001)$, in vitality $(p=0.002)$, and in social function $(p<0.001)$.

In the comparison between the RV group and the placebo group, we observed a decrease in BDI $(p<0.001)$, in STAI $(p<0.001)$, an improvement in physical function $(p<0.001)$, in role physical $(p<0.05)$, in body pain $(p<0.05)$, in general health $(p<0.001)$, in vitality $(p<0.05)$, and in social function $(p<0.001)$ (Figure 2; Table 3).

\subsection{Adverse Events}

No serious adverse events have been observed in both groups. 


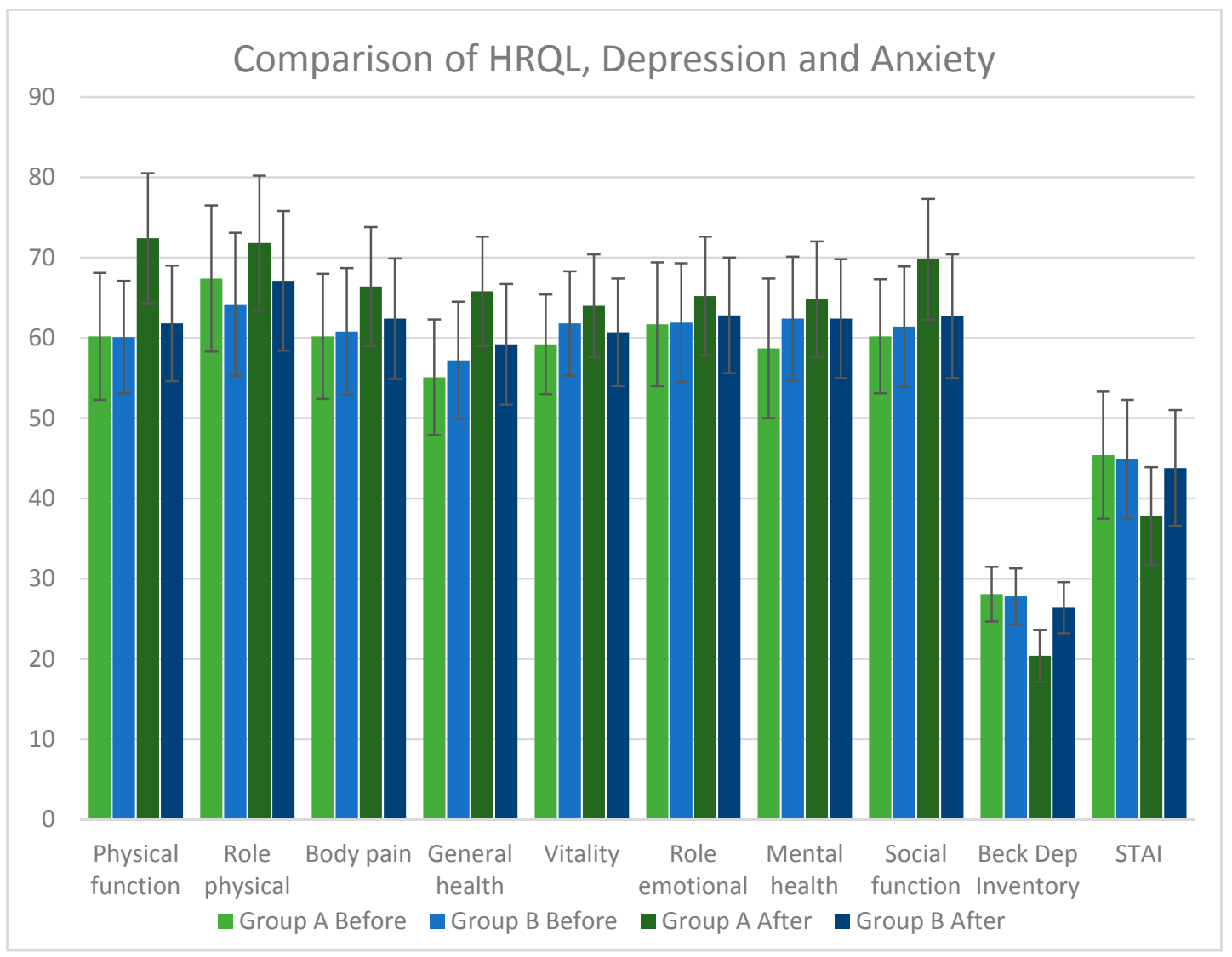

Figure 2. Comparison of health related quality of life (HRQL), Depression, and Anxiety. Group $A=$ Resveratrol Group; Group B = Placebo Group; STAI = State-Trait Anxiety Inventory.

Table 3. Comparison of HRQL, Depression, and Anxiety.

\begin{tabular}{|c|c|c|c|c|c|c|c|}
\hline \multirow{2}{*}{ Characteristics } & \multicolumn{2}{|c|}{ Resveratrol Group } & \multirow{2}{*}{$p$} & \multicolumn{2}{|c|}{ Placebo Group } & \multirow{2}{*}{$p$} & \multirow{2}{*}{$\begin{array}{c}\begin{array}{c}\text { After treatment RV vs } \\
\text { Placebo }\end{array} \\
p\end{array}$} \\
\hline & Before & After & & Before & After & & \\
\hline Physical function & $60.20 \pm 7.90$ & $72.40 \pm 8.10$ & $<0.001$ & $60.10 \pm 7.00$ & $61.80 \pm 7.20$ & N.S & $<0.001$ \\
\hline Role physical & $67.40 \pm 9.10$ & $71.80 \pm 8.40$ & N.S & $64.20 \pm 8.90$ & $67.10 \pm 8.70$ & N.S & 0.025 \\
\hline Body pain & $60.20 \pm 7.80$ & $66.40 \pm 7.40$ & 0.001 & $60.80 \pm 7.90$ & $62.40 \pm 7.50$ & N.S & 0.028 \\
\hline General health & $55.10 \pm 7.20$ & $65.80 \pm 6.80$ & $<0.001$ & $57.20 \pm 7.30$ & $59.20 \pm 7.50$ & N.S & $<0.001$ \\
\hline Vitality & $59.20 \pm 6.20$ & $64.00 \pm 6.40$ & 0.002 & $61.80 \pm 6.50$ & $60.70 \pm 6.70$ & N.S & 0.039 \\
\hline Role emotional & $61.70 \pm 7.70$ & $65.20 \pm 7.40$ & N.S & $61.90 \pm 7.40$ & $62.80 \pm 7.20$ & N.S & N.S \\
\hline Mental health & $58.70 \pm 8.70$ & $64.80 \pm 7.20$ & 0.002 & $62.40 \pm 7.70$ & $62.40 \pm 7.40$ & N.S & N.S \\
\hline Social function & $60.20 \pm 7.10$ & $69.80 \pm 7.50$ & $<0.001$ & $61.40 \pm 7.50$ & $62.70 \pm 7.70$ & N.S & $<0.001$ \\
\hline Beck Depression Inventory & $28.10 \pm 3.40$ & $20.40 \pm 3.20$ & $<0.001$ & $27.80 \pm 3.50$ & $26.40 \pm 3.20$ & N.S & $<0.001$ \\
\hline STAI & $45.40 \pm 7.90$ & $37.80 \pm 6.10$ & $<0.001$ & $44.90 \pm 7.40$ & $43.80 \pm 7.20$ & N.S & $<0.001$ \\
\hline
\end{tabular}

\section{Discussion}

In the present study, we tested a cohort of patients with MHE. Our result reveals the presence of moderate depression, anxiety, and a decrease of QoL in subjects with MHE.

The pathogenesis of MHE has been associated with impairment in cerebral energy metabolism with alteration in glucose utilization, glycolysis, and mitochondrial dysfunction. It is thought that impaired mitochondrial function and the down-regulation of the expression of key anti-oxidation enxzymes contribute to an increase in oxidative damage to membrane lipids [27-33].

It has been demonstrated that RV has remarkable health benefits. One of the major etiopathogenetic factors that are involved in the development of HE is represented by abnormal accumulation in the blood of ammonia. Nonetheless although ammonia seems to have a central role in HE, there is evidence that neurotransmission abnormalities, injury to astrocytes, and microglia activation contribute to the development of HE [34,35]. Hyperammonemia represents a major contributing factor for the 
development of HE. Recent studies have demonstrated that ammonia exerts effect on many signal transduction pathways, gene expression, and post-translational modifications and influences gene expressions via alteration in micro-RNA expression [36]. Micro-RNAs are small non-coding RNA sequences that play a role in gene silencing at the level of gene transcription as well as translation, and can be regulated by oxidative stress. In RV group we observed a decreased in ammonia serum levels, in depression, in anxiety, and an increase in quality of life (QoL).

RV improves astroglial function and it may play a role in the modulation of glutamatergic metabolism having a cytoprotective action [37,38].

Neurotransmission impairment, caused by an imbalance between the inhibitory and excitatory neurotransmission systems toward a net increase of inhibitory system, is suggested to participate in the pathogenesis of the disease. Several reported findings are consistent with an increase in $\gamma$-aminobutiric acid ergic (GABAergic) tone in $\mathrm{HE}$, such as a greater resistance to drug that decreases GABEergic agonists $[39,40]$. There is also evidence indicating disturbed glutamatergic tone, such as an increase in cortical release of glutamate (Glu) and a decrease in Glu uptake by astrocytes and neurons, leading to high Glu levels in the brain extracellular fluid, lower expression of the astroglia-specific Glu transporter, and a decrease of Glu receptors. An increase in intra-astrocytic glutamine due to the high ammonia levels seems to be a key factor for the development of Alzheimer type II astrocytes.

Microglial activation, which progresses with the development of HE and brain edema, and increases in expression of genes coding for proinflammatory cytokines have been documented in HE.

RV seems to have protective effects in geriatric disorders including Alzheimer's disease. RV can activate SIRT1, which belong to the sirtuine family of proteins [41]. SIRT1 is involved in epigenetic processes via histones and nonhistone proteins deacetylation and its-regulated pathway is associated with inflammation, cells viability, senescence, and also metabolism.

Murine models demonstrated antipsychotic and anxiolytic properties [42]. Neurological disorders are thought to occur via oxidative and and inflammatory to the CNS [43-45].

Studies have reported NF-kB, Akt and STAT3 inhibition by RV. Activation of SIRT-1, a protein recently associated with depressive-like states, inhibits NF- $\mathrm{kB}$ via histone deacetylation operated by RV [46,47]. Another SIRT-1 downstream target is represented by AKT, a serine/threonine kinase, which is linked to axonal and neuronal regulation, regeneration and survival [48,49].

RV oxidative and glial inflammation modulation had been demonstrated to prevent ammonia toxicity in astroglial cells.

High levels of ammonia can reduce serotonin and noradrenaline levels in the CNS, resulting in low alertness and attention-associated sleep complaints [10]. Neurobehavioral abnormalities are the major clinical component of $\mathrm{HE}$ and have shown to be associated with increased levels of inflammatory cytokines [50]. RV may serve as an antidepressant agent, also exerting anti-inflammatory effects [51,52] and alleviating the consequence of stress with alterations involvement in the immune functions in brain that cause deleterious modifications in the neuronal signaling [53].

The decrease in depression justifies the efficacy of RV in depressed patients with RV.

The pathophysiological mechanisms involved in HE were inflammation, oxidative stress, impaired blood-brain barrier, permeability, neurotoxins, and impaired energy metabolism of the brain [54-58].

Another pathogenic mechanism in HE associated with energy disturbances is the alteration in neurotransmission system, such as the glutamatergic and GABA-ergic systems, resulting in neuronal disinhibition. In vivo preclinical studies had also proposed the involvement of CNS neurotransmitters, including catecholamines, glutamate, GABA, histamine, serotonin, and melatonin [59-65].

In animal experimental models, RV shows a potent inhibitory monoamine oxidase A and oxidase $B$ and activate serotonine and noradrenaline system [66-70].

There are limited data showing the consequences of RV intake regarding the effects in humans.

This study has several limitations. In fact, we excluded patients with poor HRQoL due to their use of forbidden medications, which could also explain the lack of major changes. We also did not 
examine confounding factors or potential factors of depressed patients with MHE because the numbers of patients were not statistically powerful.

Such studies need to be increased in number in order to evaluate the role of RV as a modulator of behaviour in MHE patients. However, treatment of minimal HE remains a huge unmet need and a big concerted effort is needed to better defines the multiple pathophysiological mechanisms.

\section{Conclusions}

This clinical trial suggests that Resveratrol, as carnitine derivates and sylibin [71-73] is helpful in reducing ammonia serum levels and exhibit sufficient bioavailability at the dosages used without any adverse events. Thus, this study provide a rationale for further testing of resveratrol ub future clinical trials and for studying its effectiveness in treating other neurological disorders.

Acknowledgments: This study was funded by MIUR.

Author Contributions: All authors contributed in the same way to the manuscript and read and approved the final version.

Conflicts of Interest: The authors declare no conflict of interest

\section{References}

1. Malaguarnera, M.; Vacante, M.; Bertino, G.; Neri, S.; Malaguarnera, M.; Gargante, M.P.; Motta, M.; Lupo, L.; Chisari, G.; Bruno, C.M.; et al. The supplementation of acetyl-L-carnitine decreases fatigue and increases quality of life in patients with hepatitis $C$ treated with pegylated interferon- $\alpha 2 \mathrm{~b}$ plus ribavirin. J. Interferon Cytokine Res. 2011, 31, 653-659. [CrossRef] [PubMed]

2. Lewis, J.H.; Stine, J.G. Review article: Prescribing medications in patients with cirrhosis-A practical guide. Aliment. Pharmacol. Ther. 2013, 37, 1132-1156. [CrossRef] [PubMed]

3. Farris, P.; Krutmann, J.; Li, Y.-H.; McDaniel, D.; Krol, Y. Resveratrol: A unique antioxidant offering a multi-mechanistic approach for treating aging skin. J. Drugs Dermatol. 2013, 12, 1389-1394. [PubMed]

4. Švajger, U.; Jeras, M. Anti-inflammatory effects of resveratrol and its potential use in therapy of immune-mediated diseases. Int. Rev. Immunol. 2012, 31, 202-222. [CrossRef] [PubMed]

5. Campagna, M.; Rivas, C. Antiviral activity of resveratrol. Biochem. Soc. Trans. 2010, 38, 50-53. [CrossRef] [PubMed]

6. Clouser, C.L.; Chauhan, J.; Bess, M.A.; van Oploo, J.L.; Zhou, D.; Dimick-Gray, S.; Mansky, L.M.; Patterson, S.E. Anti-HIV-1 activity of resveratrol derivatives and synergistic inhibition of HIV-1 by the combination of resveratrol and decitabine. Bioorg. Med. Chem. Lett. 2012, 22, 6642-6646. [CrossRef] [PubMed]

7. Xie, X.-H.; Zang, N.; Li, S.; Wang, L.; Deng, Y.; He, Y.; Yang, X.Q.; Liu, E.M. Resveratrol Inhibits respiratory syncytial virus-induced IL-6 production, decreases viral replication, and downregulates TRIF expression in airway epithelial cells. Inflammation 2012, 35, 1392-1401. [CrossRef] [PubMed]

8. Singh, G.; Pai, R.S. Recent advances of resveratrol in nanostructured based delivery systems and in the management of HIV / AIDS. J. Control Release 2014, 194, 178-188. [CrossRef] [PubMed]

9. Aluyen, J.K.; Ton, Q.N.; Tran, T.; Yang, A.E.; Gottlieb, H.B.; Bellanger, R.A. Resveratrol: Potential as anticancer agent. J. Diet. Suppl. 2012, 9, 45-56. [CrossRef] [PubMed]

10. Yang, X.; Li, X.; Ren, J. From French Paradox to cancer treatment: Anti-cancer activities and mechanisms of resveratrol. Anti-Cancer Agents Med. Chem. 2014, 14, 806-825. [CrossRef]

11. Pennisi, M.; Bertino, G.; Gagliano, C.; Malaguarnera, M.; Bella, R.; Borzì, A.M.; Madeddu, R.; Malaguarnera, G. Resveratrol in Hepatitis C Patients Treated with Pegylated-Interferon- $\alpha$-2b and Ribavirin Reduces Sleep Disturbance. Nutrients 2017, 9, 897. [CrossRef] [PubMed]

12. Magaji, M.G.; Iniaghe, L.O.; Abolarin, M.; Abdullahi, O.I.; Magaji, R.A. Neurobehavioural evaluation of resveratrol in murine models of anxiety and schizophrenia. Metab. Brain Dis. 2017, 32, 437-442. [CrossRef] [PubMed]

13. Howitz, K.T.; Bitterman, K.J.; Cohen, H.Y.; Lamming, D.W.; Lavu, S.; Wood, J.G.; Zipkin, R.E.; Chung, P.; Kisielewski, A.; Zhang, L.L.; et al. Small molecule activators of sirtuins extend Saccharomyces cerevisiae lifespan. Nature 2003, 425, 191-196. [CrossRef] [PubMed] 
14. Krishnan, V.; Nestler, E.J. The molecular neurobiology of depression. Nature 2008, 455, 894-902. [CrossRef] [PubMed]

15. Conn, H.O. A clinical hepatologist's predictions about non-absorbed carbohydrates for the early twenty-first century. Scand. J. Gastroenterol. 1997, 222, 88-92. [CrossRef] [PubMed]

16. Child, C.G.; Turcotte, J.G. Surgery and portal hypertension. In The Liver and Portal Hypertension; Child, C.G., Ed.; Saunders: Philadelphia, PA, USA, 1964; pp. 50-64.

17. Ferenci, P.; Lockwood, A.; Mullen, K.; Tarter, R.; Weissenborn, K.; Blei, A.T. Hepatic encephalopathy-Definition, nomenclature, diagnosis, and quantification: Final report of the working party at the 11th World Congresses of Gastroenterology, Vienna, 1998. Hepatology 2002, 35, 716-721. [CrossRef] [PubMed]

18. Weissenborn, K.; Ennen, J.C.; Schomerus, H.; Rückert, N.; Hecker, H. Neuropsychological characterization of hepatic encephalopathy. J. Hepatol. 2001, 34, 768-773. [CrossRef]

19. Ware, J.; Kosinski, M.; Snow, K.K.; Gandek, B. SF-36 Health Survey: Manual and Interpretation Guide; The Health Institute, New England Medical Center: Boston, MA, USA, 1993.

20. Bonkovsky, H.L.; Woolley, J.M. Reduction of health-related quality of life in chronic hepatitis C and improvement with interferon therapy. The Consensus Interferon Study Group. Hepatology 1999, 29, $264-270$. [CrossRef] [PubMed]

21. Foster, G.R. Hepatitis C virus infection: Quality of life and side effects of treatment. J. Hepatol. 1999, 31, 250-254. [CrossRef]

22. Grosso, G.; Micek, A.; Godos, J.; Pajak, A.; Sciacca, S.; Galvano, F.; Giovannucci, E.L. Dietary Flavonoid and Lignan Intake and Mortality in Prospective Cohort Studies: Systematic Review and Dose-Response Meta-Analysis. Am. J. Epidemiol. 2017, 185, 1304-1316. [CrossRef] [PubMed]

23. Beck, A.; Steer, R.; Garbin, M. Psychometric properties of the Beck Depression Inventory: Twenty-five years of evaluation. Clin. Psychol. Rev. 1988, 8, 122-132. [CrossRef]

24. Spielberger, C.D. Manual for the State-Trait Anxiety Inventory: STAI (Form Y); Consulting Psychologists Press: Palo Alto, CA, USA, 1983.

25. Da Fonseca-Wollheim, F. Direct determination of plasma ammonia without deproteinization. An improved enzymic determination of ammonia, II (author's transl). Z. Klin. Chem. Klin. Biochem. 1973, 11, 426-431. [PubMed]

26. Latteri, S.; Malaguarnera, G.; Mannino, M.; Pesce, A.; Currò, G.; Tamburrini, S.; Scuderi, M. Ultrasound as point of care in management of polytrauma and its complication. J. Ultrasound 2017, 20, 171-177. [CrossRef] [PubMed]

27. Flamm, S.L. Covert Hepatic Encephalopathy: Who Should Be Tested and Treated? Clin. Liver Dis. 2015, 19, 473-485. [CrossRef] [PubMed]

28. Malaguarnera, G.; Latteri, S.; Catania, V.E.; Malaguarnera, M. Reduction of cardiovascular risk in subjects with high lipoprotein (a) levels. J. Thorac. Dis. 2017, 9, 2332-2336. [CrossRef] [PubMed]

29. Malaguarnera, G.; Catania, V.E.; Francaviglia, A.; Malaguarnera, M.; Drago, F.; Motta, M.; Latteri, S. Lipoprotein (a) in patients with hepatocellular carcinoma and portal vein thrombosis. Aging Clin. Exp. Res. 2017, 29, 185-190. [CrossRef] [PubMed]

30. La Verde, M.; Mule, S.; Zappala, G.; Privitera, G.; Maugeri, G.; Pecora, F.; Marranzano, M. Higher adherence to the Mediterranean diet is inversely associated with having hypertension: Is low salt intake a mediating factor? Int. J. Food Sci. Nutr. 2018, 69, 235-244. [CrossRef] [PubMed]

31. Platania, A.; Zappala, G.; Mirabella, M.U.; Gullo, C.; Mellini, G.; Beneventano, G.; Maugeri, G.; Marranzano, M. Association between Mediterranean diet adherence and dyslipidaemia in a cohort of adults living in the Mediterranean area. Int. J. Food Sci. Nutr. 2017, 1-11. [CrossRef] [PubMed]

32. Zappala, G.; Buscemi, S.; Mule, S.; La Verde, M.; D’Urso, M.; Corleo, D.; Marranzano, M. High adherence to Mediterranean diet, but not individual foods or nutrients, is associated with lower likelihood of being obese in a Mediterranean cohort. In Eating and Weight Disorders-Studies on Anorexia, Bulimia and Obesity; Springer: Berlin, Germany, 2017; pp. 1-10.

33. Bobermin, L.D.; Wartchow, K.M.; Flores, M.P.; Leite, M.C.; Quincozes-Santos, A.; Gonçalves, C.A. Ammonia-induced oxidative damage in neurons is prevented by resveratrol and lipoic acid with participation of heme oxygenase 1. Neurotoxicology 2015, 49, 28-35. [CrossRef] [PubMed]

34. Montana, V.; Verkhratsky, A.; Parpura, V. Pathological role for exocytotic glutamate release from astrocytes in hepatic encephalopathy. Curr. Neuropharmacol. 2014, 12, 324-333. [CrossRef] [PubMed] 
35. Görg, B.; Qvartskhava, N.; Bidmon, H.-J.; Palomero-Gallagher, N.; Kircheis, G.; Zilles, K.; Häussinger, D. Oxidative stress markers in the brain of patients with cirrhosis and hepatic encephalopathy. Hepatology 2010, 52, 256-265. [CrossRef] [PubMed]

36. Karababa, A.; Görg, B.; Schliess, F.; Häussinger, D. O-GlcNAcylation as a novel ammonia-induced posttranslational protein modification in cultured rat astrocytes. Metab. Brain Dis. 2014, 29, 975-982. [CrossRef] [PubMed]

37. De Almeida, L.M.V.; Piñeiro, C.C.; Leite, M.C.; Brolese, G.; Tramontina, F.; Feoli, A.M.; Gottfried, C.; Gonçalves, C.A. Resveratrol increases glutamate uptake, glutathione content, and S100B secretion in cortical astrocyte cultures. Cell. Mol. Neurobiol. 2007, 27, 661-668. [CrossRef] [PubMed]

38. Quincozes-Santos, A.; Gottfried, C. Resveratrol modulates astroglial functions: Neuroprotective hypothesis. Ann. N Y. Acad. Sci. 2011, 1215, 72-78. [CrossRef] [PubMed]

39. Felipo, V. Hepatic encephalopathy: Effects of liver failure on brain function. Nat. Rev. Neurosci. 2013, 14, 851-858. [CrossRef] [PubMed]

40. Malaguarnera, G.; Vacante, M.; Drago, F.; Bertino, G.; Motta, M.; Giordano, M.; et al. Endozepine-4 levels are increased in hepatic coma. World J. Gastroenterol. 2015, 21, 9103-9110. [CrossRef] [PubMed]

41. Poulose, S.M.; Thangthaeng, N.; Miller, M.G.; Shukitt-Hale, B. Effects of pterostilbene and resveratrol on brain and behavior. Neurochem. Int. 2015, 89, 227-233. [CrossRef] [PubMed]

42. Yáñez, M.; Fraiz, N.; Cano, E.; Orallo, F. Inhibitory effects of cis- and trans-resveratrol on noradrenaline and 5-hydroxytryptamine uptake and on monoamine oxidase activity. Biochem. Biophys. Res. Commun. 2006, 344, 688-695. [CrossRef] [PubMed]

43. Di Rosa, M.; Malaguarnera, G.; De Gregorio, C.; D’Amico, F.; Mazzarino, M.C.; Malaguarnera, L. Modulation of chitotriosidase during macrophage differentiation. Cell Biochem. Biophys. 2013, 66, 239-247. [CrossRef] [PubMed]

44. Malaguarnera, M.; Vacante, M.; Giordano, M.; Motta, M.; Bertino, G.; Pennisi, M.; Neri, S.; Malaguarnera, M.; Li Volti, G.; Galvano, F. L-carnitine supplementation improves hematological pattern in patients affected by HCV treated with Peg interferon- $\alpha 2 b$ plus ribavirin. World J. Gastroenterol. 2011, 17, 4414-4420. [CrossRef] [PubMed]

45. La Greca, G.; Santangelo, A.; Primo, S.; Sofia, M.; Latteri, S.; Russello, D.; Magro, G. Clinical and diagnostic problems of desmoid-type fibromatosis of the mesentery: Case report and review of the literature. Ann. Ital. Chir. 2014, 85.

46. Bagul, P.K.; Deepthi, N.; Sultana, R.; Banerjee, S.K. Resveratrol ameliorates cardiac oxidative stress in diabetes through deacetylation of NFkB-p65 and histone 3. J. Nutr. Biochem. 2015, 26, 1298-1307. [CrossRef] [PubMed]

47. Patki, G.; Solanki, N.; Atrooz, F.; Allam, F.; Salim, S. Depression, anxiety-like behavior and memory impairment are associated with increased oxidative stress and inflammation in a rat model of social stress. Brain Res. 2013, 1539, 73-86. [CrossRef] [PubMed]

48. Freyberg, Z.; Ferrando, S.J.; Javitch, J.A. Roles of the Akt/GSK-3 and Wnt signaling pathways in schizophrenia and antipsychotic drug action. Am. J. Psychiatry 2010, 167, 88-96. [CrossRef] [PubMed]

49. Zhang, J.; Feng, X.; Wu, J.; Xu, H.; Li, G.; Zhu, D.; Yue, Q.; Liu, H.; Zhang, Y.; Sun, D.; et al. Neuroprotective effects of resveratrol on damages of mouse cortical neurons induced by $\beta$-amyloid through activation of SIRT1/Akt1 pathway. Biofactors 2014, 40, 258-267. [CrossRef] [PubMed]

50. Aldridge, D.R.; Tranah, E.J.; Shawcross, D.L. Pathogenesis of hepatic encephalopathy: Role of ammonia and systemic inflammation. J. Clin. Exp. Hepatol. 2015, 5, S7-S20. [CrossRef] [PubMed]

51. Finnell, J.E.; Lombard, C.M.; Melson, M.N.; Singh, N.P.; Nagarkatti, M.; Nagarkatti, P.; Fadel, J.R.; Wood, C.S.; Wood, S.K. The protective effects of resveratrol on social stress-induced cytokine release and depressive-like behavior. Brain Behav. Immun. 2017, 59, 147-157. [CrossRef] [PubMed]

52. Barbagallo, F.; Latteri, S.; Sofia, M.; Ricotta, A.; Castello, G.; Chisari, A.; Randazzo, V.; La Greca, G. Appendicular tuberculosis: The resurgence of an old disease with difficult diagnosis. World J. Gastroenterol. 2010, 16, 518-521. [CrossRef] [PubMed]

53. Davinelli, S.; Scapagnini, G.; Marzatico, F.; Nobile, V.; Ferrara, N.; Corbi, G. Influence of equol and resveratrol supplementation on health-related quality of life in menopausal women: A randomized, placebo-controlled study. Maturitas 2017, 96, 77-83. [CrossRef] [PubMed]

54. Chung, S.; Yao, H.; Caito, S.; Hwang, J.-W.; Arunachalam, G.; Rahman, I. Regulation of SIRT1 in cellular functions: Role of polyphenols. Arch. Biochem. Biophys. 2010, 501, 79-90. [CrossRef] [PubMed] 
55. Pasinetti, G.M.; Wang, J.; Ho, L.; Zhao, W.; Dubner, L. Roles of resveratrol and other grape-derived polyphenols in Alzheimer's disease prevention and treatment. Biochim. Biophys. Acta 2015, 1852, 1202-1208. [CrossRef] [PubMed]

56. Jalan, R.; Olde Damink, S.W.M.; Hayes, P.C.; Deutz, N.E.P.; Lee, A. Pathogenesis of intracranial hypertension in acute liver failure: Inflammation, ammonia and cerebral blood flow. J. Hepatol. 2004, 41, 613-620. [CrossRef] [PubMed]

57. Bosoi, C.R.; Rose, C.F. Oxidative stress: A systemic factor implicated in the pathogenesis of hepatic encephalopathy. Metab. Brain Dis. 2013, 28, 175-178. [CrossRef] [PubMed]

58. Rama Rao, K.V.; Norenberg, M.D. Brain energy metabolism and mitochondrial dysfunction in acute and chronic hepatic encephalopathy. Neurochem. Int. 2012, 60, 697-706. [CrossRef] [PubMed]

59. Zwingmann, C. The anaplerotic flux and ammonia detoxification in hepatic encephalopathy. Metab. Brain Dis. 2007, 22, 235-249. [CrossRef] [PubMed]

60. Yurdaydin, C.; Hörtnagl, H.; Steindl, P.; Zimmermann, C.; Pifl, C.; Singer, E.A.; Roth, E.; Ferenci, P. Increased serotoninergic and noradrenergic activity in hepatic encephalopathy in rats with thioacetamide-induced acute liver failure. Hepatology 1990, 12, 695-700. [CrossRef] [PubMed]

61. Lozeva, V.; Tuomisto, L.; Sola, D.; Plumed, C.; Hippeläinen, M.; Butterworth, R. Increased density of brain histamine $\mathrm{H}(1)$ receptors in rats with portacaval anastomosis and in cirrhotic patients with chronic hepatic encephalopathy. Hepatology 2001, 33, 1370-1376. [CrossRef] [PubMed]

62. Steindl, P.E.; Finn, B.; Bendok, B.; Rothke, S.; Zee, P.C.; Blei, A.T. Disruption of the diurnal rhythm of plasma melatonin in cirrhosis. Ann. Intern. Med. 1995, 123, 274-277. [CrossRef] [PubMed]

63. Schafer, D.F.; Jones, E.A. Hepatic encephalopathy and the gamma-aminobutyric-acid neurotransmitter system. Lancet 1982, 319, 18-20. [CrossRef]

64. Ahboucha, S.; Pomier-Layrargues, G.; Butterworth, R.F. Increased brain concentrations of endogenous (non-benzodiazepine) GABA-A receptor ligands in human hepatic encephalopathy. Metab. Brain Dis. 2004, 19, 241-251. [CrossRef] [PubMed]

65. Als-Nielsen, B.; Gluud, L.L.; Gluud, C. Dopaminergic agonists for hepatic encephalopathy. Cochrane Database Syst. Rev. 2004, 18. [CrossRef]

66. De Oliveira, M.R.; Chenet, A.L.; Duarte, A.R.; Scaini, G.; Quevedo, J. Molecular Mechanisms Underlying the Anti-depressant Effects of Resveratrol: A Review. Mol. Neurobiol. 2017, 55, 1-17. [CrossRef] [PubMed]

67. Xu, Y.; Wang, Z.; You, W.; Zhang, X.; Li, S.; Barish, P.A.; Vernon, M.M.; Du, X.; Li, G.; Pan, J.; et al. Antidepressant-like effect of trans-resveratrol: Involvement of serotonin and noradrenaline system. Eur. Neuropsychopharmacol. 2010, 20, 405-413. [CrossRef] [PubMed]

68. Zhao, X.; Yu, C.; Wang, C.; Zhang, J.-F.; Zhou, W.H.; Cui, W.-G.; Ye, F.; Xu, Y. Chronic resveratrol treatment exerts antihyperalgesic effect and corrects co-morbid depressive like behaviors in mice with mononeuropathy: Involvement of serotonergic system. Neuropharmacology 2014, 85, 131-141. [CrossRef] [PubMed]

69. Nawaz, W.; Zhou, Z.; Deng, S.; Ma, X.; Ma, X.; Li, C.; Shu, X. Therapeutic Versatility of Resveratrol Derivatives. Nutrients 2017, 9, 1188. [CrossRef] [PubMed]

70. Grosso, G.; Godos, J.; Lamuela-Raventos, R.; Ray, S.; Micek, A.; Pajak, A.; Sciacca, S.; D'orazio, N.; Del Rio, D.; Galvano, F. A comprehensive meta-analysis on dietary flavonoid and lignan intake and cancer risk: Level of evidence and limitations. Mol. Nutr. Food Res. 2017, 61. [CrossRef] [PubMed]

71. Malaguarnera, M. Acetyl-L-carnitine in hepatic encephalopathy. Metab. Brain Dis. 2013, 28, $193-199$. [CrossRef] [PubMed]

72. Malaguarnera, G.; Bertino, G.; Chisari, G.; Motta, M.; Vecchio, M.; Vacante, M.; Caraci, F.; Greco, C.; Drago, F.; Nunnari, G.; et al. Silybin supplementation during HCV therapy with pegylated interferon- $\alpha$ plus ribavirin reduces depression and anxiety and increases work ability. BMC Psychiatry 2016, 16, 398. [CrossRef] [PubMed]

73. Malaguarnera, M.; Bella, R.; Vacante, M.; Giordano, M.; Malaguarnera, G.; Gargante, M.P.; Motta, M.; Mistretta, A.; Rampello, L.; Pennisi, G. Acetyl-L-carnitine reduces depression and improves quality of life in patients with minimal hepatic encephalopathy. Scand. J. Gastroenterol. 2011, 46, 750-759. [CrossRef] [PubMed]

(C) 2018 by the authors. Licensee MDPI, Basel, Switzerland. This article is an open access article distributed under the terms and conditions of the Creative Commons Attribution (CC BY) license (http:/ / creativecommons.org/licenses/by/4.0/). 